\title{
Online Self-Regulatory Learning Behaviors as a Mediator in the Relationship between Online Course Perceptions with Achievement
}

\author{
Lucy Barnard, Valerie Paton and William Lan \\ Texas Tech University \\ USA
}

\begin{abstract}
Positive perceptions of online course communication and collaboration have been associated with better academic outcomes, while self-regulatory learning behaviors have also been linked to academic achievement and other positive learning outcomes. In the current study, we examined whether self-regulatory learning behaviors may be considered as mediating the relationship between student perceptions of online course communication and collaboration with academic achievement as measured by grade point average (GPA). Results indicate that online selfregulatory learning behaviors, though not strongly associated with academic achievement in and of themselves, do mediate the positive relationship between student perceptions of online course communication and collaboration with academic achievement.
\end{abstract}

Keywords: Self-regulation; online learning; achievement

\section{Introduction}

As part of the annual Sloan-C online survey, chief academic officers at institutions of higher education across the nation indicated that "a barrier to widespread adoption of online learning" was the fact that "students need more discipline to succeed in online courses" (Allen \& Seaman, 2006, p. 13). The importance of self-regulation in improving learning outcomes in online and face-to-face formats cannot be overstated. Research literature has concluded that students who are more able to regulate their learning perform better than those students who are less able to regulate their learning (Schunk \& Zimmerman, 1998; Zimmerman \& Schunk, 2001). Selfregulated learning has been referred to as the desired outcome of the process of "students' selfgenerated thoughts and behaviors that are systematically oriented toward the attainment of their learning goals" (Zimmerman \& Schunk, 2001, p. 125). Self-regulation as such can be viewed as the requisite discipline of the individual in their learning process, whether this process takes place in an online or face-to-face environment. Examples of self-regulatory behaviors in learning include, but are not limited to, goal setting and environment structuring. Some of these selfregulatory behaviors, like goal setting, appear to be more explicit, while others, like environment structuring (e.g., turning off a television while you work), appear to be more implicit. Whether implicit or explicit, these self-regulatory behaviors do have an effect on the achievement and performance of learners. 
Online Self-Regulatory Learning Behaviors as a Mediator

in the Relationship between Online Course Perceptions with Achievement

Barnard, Paton \& Lan

Bandura (1997) has emphasized the ability to self-regulate as the ability to exercise control over one's behavior, which suggests evidence towards the role of an individual's cognition in their observed behaviors. The influence an individual's cognitive ability to self-regulate stands in contrast to behaviorist perspectives on learning and is unique to Bandura's $(1986$; 1997) social cognitive perspective. From a social cognitive perspective, Zimmerman and Schunk (2001) postulate that the ability to self-regulate one's learning develops in a cyclical nature as the interaction of personal, behavioral, and environmental factors. As self-regulatory skills develop across time, the source of influence appears to shift from environmental to more personal factors with behavioral factors providing feedback (Zimmerman \& Schunk, 2001). As applied to learners in online environments, the development of self-regulatory skills would appear to first derive from the online learning environment factors, where learners would receive feedback from their behaviors in these online environments (e.g., lack of checking in online leading to missed assignment deadlines, etc.). While self-regulatory behaviors in online learning environments would appear to develop similarly as in other domains, self-regulatory behaviors have been indicated as being "highly context dependent" (Zimmerman \& Schunk, 2001, p.125) requiring the examination of self-regulatory behaviors within the context of the online learning environment.

Online and distance learning environments are, indeed, unique contexts requiring examination. Moore $(1991$; 1993) discusses the unique context of the distance or online learning environment from the perspective of teacher-learner relationships. According to Moore $(1991 ; 1993)$, the teacher and learner in online or distance learning are always separated by space and sometimes both time and space. This separation by space creates a psychological or transactional distance between the learner and instructor. The degree to which this transactional distance effects the teacher-learner relationship appears to be the function of three clusters of variables referred to as: (a) dialogue, (b) structure, and (c) learner autonomy (Moore, 1993). Moore's learner autonomy can be likened to the ability of learner's self-regulation from the social cognitive perspective. Moore (1993) defines learner autonomy as "the extent to which in the teaching/ learning relationship it is the learner rather than the teacher who determines the goals, the learning experiences, and the evaluation of decisions. .." (p. 31). From the perspective of the theory of transactional distance, learners who are more autonomous or self-regulated appear to be more comfortable in online or distance programs than learners who are less autonomous or selfregulated (Moore, 1993, p. 32). For online courses in particular, Howland and Moore (2002) have indicated that self-regulatory learning behaviors were important for courses delivered through the Internet, and as being associated with more positive academic outcomes including student retention and program satisfaction. In examining the open-ended responses of 48 online students, Howland and Moore (2002) additionally found that students who engaged in more online selfregulatory learning behaviors generally had more positive perceptions of online courses. The magnitude and form of the relationship among student perceptions of online course communication and collaboration, self-regulatory learning behaviors, and academic achievement in online courses, however, has yet to be quantitatively examined.

In a qualitative study of online course curriculum and instruction, Fisher and Baird (2005) found that fostering a sense of community positively influenced student retention over the course of a period of two years. Noting that this sense of community and support felt by students was associated with increased online self-regulatory learning behaviors, Fisher and Baird also found that students engaging in communication online tended to want to meet peer expectations and to be valued in the eyes of their peers, and thus were more likely to choose to engage in online selfregulatory learning behaviors to meet those expectations. Fisher and Baird concluded two means of encouraging student self-regulation was (a) peer evaluations and (b) small group projects which served to create an online learning environment wherein students feel accountable to meet 
Online Self-Regulatory Learning Behaviors as a Mediator

in the Relationship between Online Course Perceptions with Achievement

Barnard, Paton \& Lan

the expectations of others. In this way, Fisher and Baird (2005) highlight means of improving student learning by priming a social interaction schema within the learner, essentially fueling their sense of social agency. Due to the student-desired end of social acceptance and desirability by others, collaborative group activities serves as means of improving student online learning.

The purpose of this study was to examine whether online self-regulatory learning behaviors in online courses may be considered as mediating the relationship between student perceptions of online course communication and collaboration with academic achievement. To achieve the purpose of this study, we employed structural equation modeling as an advanced statistical means of examining mediating relationships (Bollen, 1989). From a review of the literature, it is clear that student perceptions of online course communication and collaboration are positively associated with academic achievement and more positive academic outcomes (see Fisher \& Baird, 2005; Howland \& Moore, 2002; Lee \& Gibson, 2003). The question therefore becomes: By what mechanism(s) does this positive relationship between student perceptions of online course communication and collaboration and academic achievement occur? In this study, we examine whether online self-regulatory learning behaviors mediate the relationship between student perceptions of online courses and academic achievement.

One explanation may be an issue of self-selection bias, where students who have better achievement in online courses would of course have better perceptions of online courses in general, including course communication and collaboration. Not all students who succeed in online courses, however, hold positive perceptions of online course communication and collaboration. In a study of 231 students enrolled in online or distance programs, Barnard, Paton, and Rose (2007) found that students' self-reported perceptions of online course communication and collaboration appeared to differ as a matter of degree program. Students enrolled in programs categorized as more hard sciences, such as engineering, tended to have less positive perceptions than students enrolled in more soft sciences, such as education. Indeed, student enrolled in the soft sciences tended to hold more positive perceptions of online course communication and collaboration.

Another explanation as to this positive relationship between student perceptions of online course communication and collaboration and academic achievement is that online self-regulatory learning behaviors serves as catalyst or means through which student perceptions of online course communication and collaboration translate into academic outcomes. We hypothesize that students who have more positive perceptions of online course communication and collaboration will engage in more online self-regulatory learning behaviors, which, in turn, is positively associated with academic achievement and vice-versa. While these self-regulatory learning behaviors cannot completely mediate the positive relationship between student perceptions of online course communication and collaboration and academic achievement, self-regulation in online learning environments has been found to be influential to student success in computer-mediated curriculum and instruction (King, Harner \& Brown, 2000).

\section{Participants}

\section{Method}

The study consisted of a sampling frame of 628 unduplicated students with working (i.e., deliverable) email addresses enrolled in online courses at a large, public university located in the Southwestern United States. Of these students taking online courses, 204 self-selected to complete the online survey by responding to a recruitment email message. Participants were 
Online Self-Regulatory Learning Behaviors as a Mediator

in the Relationship between Online Course Perceptions with Achievement

Barnard, Paton \& Lan

informed as to the voluntary nature of the study and assured as to the confidentiality of their responses. Approximately 36 percent of the participants identified themselves as male $(n=73)$ and 82.6 percent as white $(\mathrm{n}=168)$. The mean age of the participants was 38 , with a standard deviation of 9.93, ranging from 22 to 65 years of age. Approximately 82 percent of the participants $(n=167)$ were studying online at the graduate or post-baccalaureate level (e.g., teacher certification). Respondents were enrolled in 24 different academic degree programs and listed home addresses in 146 different US postal zip codes.

\section{Measures}

For the outcome variable of academic achievement, the current, cumulative grade point averages (GPAs) of the participants were obtained from the university. Students who participated in the study had GPAs that ranged from 2.00 to 4.00 , with a mean of 3.73 and standard deviation of 41 . As the sample consisted mainly of students studying at the graduate or post-baccalaureate level, GPAs being positively-skewed may be considered typical. The GPAs reflect grade points earned from coursework offered online or at a distance. To measure student perceptions of online course communication and collaboration, an 11-item scale with a 5-point Likert-type response format with values ranging from strongly agree (5) to strongly disagree (1) was constructed (Rose, 2006). Higher total scale scores on this scale indicate more positive perceptions toward online course communication and collaboration, while lower total scale scores indicate less positive perceptions. Positive perceptions of online course communication and collaboration can be defined as the willingness of individuals to be engaged in online communication and collaboration. This 11-item scale revealed an acceptable internal consistency of scores obtained from the scale with $\alpha=.94$. Nunnally (1978) has suggested that score reliability of .70 or better is acceptable when used in basic social science research, such as in this study. Barnard, Paton, and Rose (2007) present a fully accessible copy of all items on this scale including further psychometric information. Examples of two items from the scale are as follows:

- I felt like I was part of a community with my classmates in my online course.

- Online classes without collaborative (group) activities make me feel isolated from my classmates and/ or alone.

To measure self-regulation in online learning, a short form of the Online Self-regulated Learning Questionnaire (OSLQ) was employed. The short form of the Online Self-regulated Learning Questionnaire (OSLQ) is a 24-item scale with a 5-point Likert-type response format having values ranging from strongly agree (5) to strongly disagree (1). Higher scores on this scale indicate better self-regulation in online learning by students. The short form was developed from an 86-item long form of the instrument by examining internal consistency and exploratory factor analyses results for data collected from the long form. The long form of the instrument was developed to reflect a multi-dimensional conception of self-regulated learning as derived from the 1998 work of Zimmerman (Lan, Bremer, Stevens \& Mullen, 2004). In contrast to the long form of the instrument, the short form consists of six important constructs of self-regulation in online learning, namely: (a) environment structuring; (b) goal setting; (c) time management; (d) help seeking; (e) task strategies; (f) and self-evaluation. The internal consistency of scores obtained for the short form of the OSLQ in study was $\alpha=.93$. Table 2 (see appendix) contains all items of the OSLQ along with subscale designation. Examples of two items from the time management and goal setting aspects of the scale respectively from the short form are as follows: 
Online Self-Regulatory Learning Behaviors as a Mediator

in the Relationship between Online Course Perceptions with Achievement

Barnard, Paton \& Lan

- Although we don't have to attend daily classes, I still try to distribute my studying time evenly across days.

- I set standards for my assignments in online courses.

\section{Procedure}

All measures were administered online along with a series of demographic questions. All participants were assured that their responses would remain confidential when recruited for their participation. Data were imported from the online survey into a Microsoft Excel format and then imported into SPSS (v. 12.0). Structural equation modeling analyses were performed in MPlus (v. 4.20). Values for missing data were handled using full information maximum-likelihood (FIML) as the method of estimation. As an extension of maximum likelihood, FIML takes advantage of all possible data points in analysis. Enders and Bandalos (2001) have indicated that full information maximum-likelihood is superior to list-wise, pair-wise, and similar response pattern imputations in handling missing data that may be considered ignorable.

\section{Analysis}

To examine whether self-regulation in online learning may be considered as mediating the relationship between student perceptions of online course communication and collaboration and academic achievement, we utilized structural models (see Figure 1). Direct and indirect effects were calculated using MPlus (v. 4.20). Five statistics reflecting fit were reported: the chi-square statistic; the ratio of chi-square statistic to degrees of freedom; the root mean square error of approximation (RMSEA); the Tucker Lewis Index (TLI), also known as the Non Normed Fit Index (NNFI); and the Comparative Fit Index (CFI). No post hoc model modifications were made.

\section{Results}

In modeling the student self-regulation in online learning as a mediator in the relationship between student perceptions of online course communication and collaboration and achievement, the chi-square goodness-of-fit statistic was significant, indicating that the model may not fit the data, $\chi 2(622)=917.31, p<.05$. The chi-square statistic, however, has been indicated as being sensitive to sample size, thus an adjunct discrepancy-based fit index may be used as the ratio of chi-square to degrees of freedom $\left(\chi^{2} / \mathrm{df}\right)$. A $\chi^{2} / \mathrm{df}$ ratio value less than 5 has been suggested as indicating an acceptable fit between the hypothesized model and the sample data (MacCallum, Brown \& Sugawara, 1996). With a $\chi 2 / \mathrm{df}$ ratio value of 1.47 , the proposed model may have an acceptable fit. The root mean square error of approximation (RMSEA) as compensating for the effects of model complexity was 0.05, which according to Browne and Cudek (1993) indicates an acceptable fit of the model being less than or close to 0.05 . The value of Tucker Lewis Index (TLI), also known as the Non Normed Fit Index (NNFI) was .94 and value of the Comparative Fit Index (CFI) was .93. Hu and Bentler (1999) note that fit index values of .95 (or close to it) are indicative of good fit. Thus, the model appears to fit the data well as seen in Figure 1. The paths in the model were all significant with standardized values ranging from .46 to .94 . Table 1 contains the standardized path coefficients from the latent variable constructs to the items for both scales and from the higher order construct of online self-regulation to the latent variable subscales of the OSLQ. 
Online Self-Regulatory Learning Behaviors as a Mediator in the Relationship between Online Course Perceptions with Achievement Barnard, Paton \& Lan

The relationship between student perceptions of online course communication and collaboration and student GPA was moderately strong and positive with a standardized path coefficient value of .43, which was significant at the .01 level (see Figure 1). As student perceptions of online course communication and collaboration increase, academic achievement as measured by GPA appears to increase as well. Additionally, the relationship between online learning self-regulation and student perceptions of online course communication and collaboration appeared to be strong and positive with a standardized path coefficient value of .70, which was significant at the .01 level. As student perceptions of online course communication and collaboration increase, student selfregulation in online learning as measured by the short form of the OSLQ appears to increase as well. The relationship between student self-regulation in online learning and academic achievement (e.g., GPA) was weak and positive with a standardized path coefficient value of .18, which was significant at the .05 level. As student self-regulation in online learning is higher, academic achievement as measured by GPA appears to be better as well. In modeling the extent of this mediating relationship in MPlus (v. 4.20), the indirect effect of self-regulation in online learning between student perceptions of online course communication and collaboration and GPA was a standardized path coefficient value of .13 , which was significant at the .05 level. These results indicate that student self-regulation in online learning may be considered as positively mediating the relationship between student perceptions of online course communication and collaboration and achievement as measured by GPA. As student self-regulation in online learning increases, student perceptions of online course communication and collaboration increase which, in turn, is positively associated with academic achievement.

Figure 1. Path diagram with online learning self-regulation as a mediator

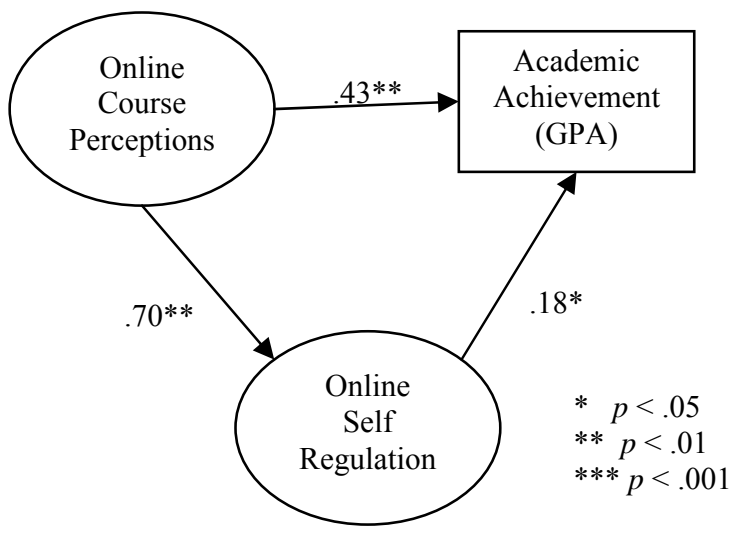


Online Self-Regulatory Learning Behaviors as a Mediator in the Relationship between Online Course Perceptions with Achievement

Barnard, Paton \& Lan

Table 1. Standardized path coefficients from latent to observed variables

\begin{tabular}{|c|c|c|c|c|c|}
\hline 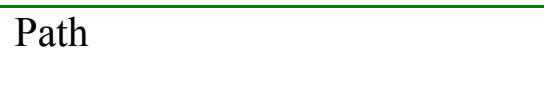 & $\begin{array}{l}\text { Std. } \\
\text { Coeff. }\end{array}$ & Path & & & Std. Coeff. \\
\hline Perceptions of Online Course C & ommun & on \& Coll & aboration & & \\
\hline Online Perceptions $\rightarrow$ OPQ1 & .64 & $\begin{array}{l}\text { Online } \\
\text { OPQ7 }\end{array}$ & Perceptions & $\rightarrow$ & .81 \\
\hline Online Perceptions $\rightarrow$ OPQ2 & .83 & $\begin{array}{l}\text { Online } \\
\text { OPQ8 }\end{array}$ & Perceptions & $\rightarrow$ & .83 \\
\hline Online Perceptions $\rightarrow$ OPQ3 & .87 & $\begin{array}{l}\text { Online } \\
\text { OPQ99 }\end{array}$ & Perceptions & $\rightarrow$ & .77 \\
\hline Online Perceptions $\rightarrow$ OPQ4 & .86 & $\begin{array}{l}\text { Online } \\
\text { OPQ10 }\end{array}$ & Perceptions & $\rightarrow$ & .78 \\
\hline Online Perceptions $\rightarrow$ OPQ5 & .78 & $\begin{array}{l}\text { Online } \\
\text { OPQ11 }\end{array}$ & Perceptions & $\rightarrow$ & .53 \\
\hline $\begin{array}{l}\text { Online Perceptions } \rightarrow \text { OPQ6 } \\
\text { Online Self-Regulated Learning }\end{array}$ & $\begin{array}{l}.63 \\
\text { by Sub }\end{array}$ & & & & \\
\hline $\begin{array}{l}\text { Environment Structuring } \rightarrow \\
\text { ESQ1 }\end{array}$ & .81 & Help Se & king $\rightarrow$ HSQ13 & & .53 \\
\hline $\begin{array}{l}\text { Environment Structuring } \rightarrow \\
\text { ESQ2 }\end{array}$ & .87 & Help Se & king $\rightarrow$ HSQ14 & & .73 \\
\hline $\begin{array}{l}\text { Environment Structuring } \rightarrow \\
\text { ESQ3 }\end{array}$ & .86 & Help Se & king $\rightarrow$ HSQ15 & & .44 \\
\hline $\begin{array}{l}\text { Environment Structuring } \rightarrow \\
\text { ESQ4 }\end{array}$ & .79 & Help Se & king $\rightarrow$ HSQ16 & & .37 \\
\hline Goal Setting $\rightarrow$ GSQ5 & .79 & Task Str & ategies $\rightarrow$ TSQ1 & & .63 \\
\hline Goal Setting $\rightarrow$ GSQ6 & .80 & Task Str & ategies $\rightarrow$ TSQ 1 & & .56 \\
\hline Goal Setting $\rightarrow$ GSQ7 & .79 & Task Str & ategies $\rightarrow$ TSQ 1 & & .57 \\
\hline Goal Setting $\rightarrow$ GSQ8 & .85 & Task Str & ategies $\rightarrow$ TSQ2 & & .64 \\
\hline Goal Setting $\rightarrow$ GSQ9 & .58 & Self Eva & luation $\rightarrow$ SEQ2 & & .61 \\
\hline Time Management $\rightarrow$ TMQ10 & .74 & Self Eva & luation $\rightarrow$ SEQ2 & & .40 \\
\hline Time Management $\rightarrow$ TMQ11 & .70 & Self Eva & luation $\rightarrow$ SEQ2 & & .80 \\
\hline Time Management $\rightarrow$ TMQ12 & .72 & Self Eva & luation $\rightarrow$ SEQ2 & & .78 \\
\hline Higher order paths to latent sub & cales o & LQ & & & \\
\hline $\begin{array}{l}\text { Online Self-Regulation } \rightarrow \\
\text { Environment Structuring }\end{array}$ & .54 & $\begin{array}{l}\text { Online } \\
\text { Goal Se }\end{array}$ & $\begin{array}{l}\text { elf-Regulation } \\
\text { ting }\end{array}$ & & .34 \\
\hline $\begin{array}{l}\text { Online Self-Regulation } \rightarrow \\
\text { Time Management }\end{array}$ & .62 & $\begin{array}{l}\text { Online } \\
\text { Help Se }\end{array}$ & $\begin{array}{l}\text { elf-Regulation } \\
\text { king }\end{array}$ & & .72 \\
\hline $\begin{array}{l}\text { Online Self-Regulation } \rightarrow \\
\text { Task Strategies }\end{array}$ & .47 & $\begin{array}{l}\text { Online } S \\
\text { Self Eva }\end{array}$ & $\begin{array}{l}\text { elf-Regulation } \rightarrow \\
\text { luation }\end{array}$ & & .65 \\
\hline
\end{tabular}


Online Self-Regulatory Learning Behaviors as a Mediator

in the Relationship between Online Course Perceptions with Achievement

Barnard, Paton \& Lan

\section{Discussion}

As hypothesized, online self-regulatory learning behaviors appear to be positively mediating the relationship between students' perceptions of online course communication and collaboration and academic achievement. Online self-regulatory learning behaviors were only weakly associated with better academic achievement by themselves. The indirect effect of online self-regulatory learning behaviors was estimated with a standardized path coefficient value of .13, while the direct effect of perceptions of online course communication and collaboration with academic achievement was estimated with a standardized path coefficient value of .43 (both significant at the .05 level; see Figure 1). This result indicates that approximately one third of the association between student perceptions of online course communication and collaboration and academic achievement may be accounted for by online self-regulatory learning behaviors. While online self-regulatory learning behaviors do not appear to be that strongly associated with academic achievement, self-regulatory learning behaviors do appear to mediate and account for a significant amount of the positive relationship between student perceptions of online course communication and collaboration with academic achievement. In other words, online selfregulatory learning behaviors do mediate the relationship between perceptions of online courses and academic achievement. As online self-regulatory learning behaviors increase, the relationship between perceptions of online course communication and academic achievement also strengthens.

Results clearly indicate that as student perceptions of online course communication and collaboration become more positive, their self-reported degree of self-regulation in online learning also increases with a standardized path coefficient value of .70 . Students who report higher levels of self-regulation in online courses appear to have better perceptions of online course communication and collaboration; students who have less positive perceptions of online course communication and collaboration report lesser levels of self-regulation in online courses. Additionally, the results of this study indicate that as student perceptions of online course communication and collaboration become more positive, their academic achievement as measured by GPA also improves, which is supported by extant research literature (e.g. Fisher \& Baird, 2005; Howland \& Moore, 2002; Lee \& Gibson, 2003).

While it appears that student self-regulation in online learning is not strongly related to academic achievement as measured by GPA (see Figure 1), this finding does not negate the importance of self-regulatory learning behaviors, but informs online instruction and course design. We suggest that students must first have positive perceptions of online course communication and collaboration in order to engage in self-regulated learning in the online classroom to a sufficient degree that it may positively influence academic achievement as measured by GPA. This research indicates that the prerequisite variable of positive perceptions of online course communication and collaboration may also lend to self-regulatory behaviors in online learning, which mediates higher academic achievement as measured by GPA. Other variables not examined may also serve the function as additional prerequisites to self-regulation in online learning. We suggest that instructors and designers of online course curricula be especially concerned with creating learning environments where positive perceptions toward online course communication and collaboration may be formed and fostered.

Future research should re-examine this mediating relationship of self-regulation in online learning between student perceptions of online course communication and collaboration and academic achievement as measured by GPA so as to further validate findings. Additionally, lack of sufficient sample size did not permit the multi-group modeling of this mediating model as shown 
Online Self-Regulatory Learning Behaviors as a Mediator in the Relationship between Online Course Perceptions with Achievement Barnard, Paton \& Lan

in Figure 1. Multi-group modeling in SEM permits the properties of a model to be assessed across groups (Joreskog, 1971). Gender differences in this mediating relationship, along with other relevant variables, could be examined using multi-group modeling.

\section{References}

Allen, I. E., \& Seaman, J. (2006). Making the grade: Online education in the United States, 2006. Needham, MA.: Sloan-C.

Bandura, A. (1997). Self-efficacy: The exercise of control. New York: Freeman.

Bandura, A. (1986). Social foundations of thought and action: A social cognitive. Englewood Cliffs, NJ.: Prentice Hall.

Barnard, L., Paton, V. O., \& Rose, K. (2007). Perceptions of online course communications and collaboration. Online Journal of Distance Learning Administration, 10(4). http://www.westga.edu/ distance/ojdla/winter104/barnard104.html

Bollen, K. A. (1989). Structural equations with latent variables. New York: John Wiley \& Sons.

Browne, M. W., \& Cudek, R. (1993). Alternative ways of assessing models fit. In K. A. Bollen \& J. S. Long (Eds.), Testing structural equation models. (pp. 136-162). Newbury Park, CA.: Sage Publications.

Enders, C. K., \& Bandalos, D. L. (2001). The relative performance of full information maximum likelihood estimation for missing data in structural equation models. Structural Equation Modeling: A Multidisciplinary Journal, 8, 430-457.

Fisher, M., \& Baird, D. E. (2005). Online learning design that fosters student support, selfregulation, and retention. Campus-Wide Information Systems, 22(5), 88-107.

Howland, J. L., \& Moore, J. L. (2002). Student perceptions as distance learners in Internet-based courses. Distance Education, 23(2), 183-195.

Hu, L., \& Bentler, P. M. (1999). Cutoff criteria for fit indices in covariance structure analysis: Conventional criteria versus new alternatives. Structural Equation Modeling, 6(1), 1-55.

Joreskog, K. G. (1971). Simultaneous factor analysis in several populations. Psychometrika, 36, 409-426.

King, F. B., Harner, M., \& Brown, S. W. (2000). Self-regulatory behavior influences in distance learning. International Journal of Instructional Media, 27(2), 147-153.

Lan, W. Y., Bremer, R., Stevens, T., \& Mullen, G. (2004). Self-regulated learning in the online environment. Paper presented at the 2004 annual meeting American Educational Research Association, April 7-8, San Diego.

Lee, J., \& Gibson, C. C. (2003). Developing self-direction in an online course through computermediated interaction. The American Journal of Distance Education, 17(3), 173-187. 
Online Self-Regulatory Learning Behaviors as a Mediator in the Relationship between Online Course Perceptions with Achievement Barnard, Paton \& Lan

MacCallum, R. C., Browne, M. W., \& Sugawara, H. M. (1996). Power analysis and determination of sample size for covariance structure modeling. Psychological Methods, 1(2), 130-149.

Moore, M. G. (1993). Theory of transactional distance. In D. Keegan (Ed.), Theoretical principles of distance education (pp. 22-38). New York: Routledge.

Moore, M. G. (1991). Distance education theory. The American Journal of Distance Education, $5(3), 1-6$.

Nunnally, J. C. (1978). Psychometric theory (2nd ed.). New York: McGraw-Hill.

Rose, K. (2006, May). Building Online Learner Communities: Survey Summary. Unpublished master's thesis, Texas Tech University, Lubbock, Texas.

Schunk, D. H., \& Zimmerman, B. J. (1998). Self-regulated learning: From teaching to selfreflective practice. New York: London.

Zimmerman, B. J. (1998). Academic studying and the development of personal skill: A selfregulatory perspective. Educational Psychologist, 33, 73-86.

Zimmerman, B. J., \& Schunk, D. H. (2001). Self-regulated learning and academic achievement: Theoretical perspectives (2nd ed.). Mahwah, NJ.: Lawrence Erlbaum Associates.

\section{Appendix}

Short form of the Online Self-regulated Learning Questionnaire

Item

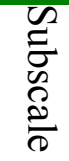

I set standards for my assignments in online courses.

Goal Setting

I set short-term (daily or weekly) goals as well as long-term goals Goal Setting (monthly or for the semester).

I keep a high standard for my learning in my online courses.

Goal Setting

I set goals to help me manage studying time for my online courses.

Goal Setting

I don't compromise the quality of my work because it is online.

Goal Setting

I choose the location where I study to avoid too much distraction.

I find a comfortable place to study.

Environment

Structuring

Environment

Structuring

I know where I can study most efficiently for online courses.

Environment

Structuring 
I choose a time with few distractions for studying for my online courses.

I try to take more thorough notes for my online courses because notes are even more important for learning online than in a regular classroom.

I read aloud instructional materials posted online to fight against distractions.

I prepare my questions before joining in the chat room and Task Strategies discussion.

I work extra problems in my online courses in addition to the Task Strategies assigned ones to master the course content.

I allocate extra studying time for my online courses because I know it is time-demanding.

I try to schedule the same time every day or every week to study for my online courses, and I observe the schedule.

Although we don't have to attend daily classes, I still try to distribute my studying time evenly across days.

I find someone who is knowledgeable in course content so that I can consult with him or her when I need help.

I share my problems with my classmates online so we know what we are struggling with and how to solve our problems.

If needed, I try to meet my classmates face-to-face.

I am persistent in getting help from the instructor through e-mail.

I summarize my learning in online courses to examine my Self-Evaluation understanding of what I have learned.

I ask myself a lot of questions about the course material when Self-Evaluation studying for an online course.

I communicate with my classmates to find out how I am doing in my Self-Evaluation online classes.

I communicate with my classmates to find out what I am learning Self-Evaluation that is different from what they are learning. 